\title{
Nasib Bahasa Jawa dan Bahasa Indonesia dalam Pandangan dan Sikap Bahasa Generasi Muda Jawa
}

\author{
Suharyo \\ Fakultas Ilmu Budaya, Universitas Diponegoro \\ haryo.sastra@gmail.com
}

\begin{abstract}
This study aims to reveal the fate of the Java language on the one hand and the Indonesian language on the other hand through the selection and defense of language (Indonesia and Java) by the younger generation. How young people choose language as a means of expression in the realm of house and the realm of friendship. (A) determining the location and population and sample, (b) questionnaire distribution to a number of respondents who were then analyzed qualitatively and quantitatively, (c) nonparticipant observation in the daily life of the younger generation, (d) structured interviews and depth using snowball method which then analyzed qualitatively. The population of this research is the entire younger generation of Javanese who live in Central Java. The target population of this study is the younger generation of the various regions who live in Solo, Boyolali, Pekalongan, and Tegal, while the sample was selected randomly. The result shows that (1) the younger generation of Java uses more BI (Bahasa Indonesia) than Javanese (BJ) both in the home and friendship, (2) the young generation of Java will use 100\% BI when someday have a spouse, (3) the younger generation of Java has a negative attitude towards BJ, being ignorant of BI, and not proud of BI, (4) the younger generation is more familiar with the vocabulary such as downloads, stakeholders, gadgets, than in BI, and (5) estimated BJ (especially manners) in the next 2 or 3 generations will be abandoned by the younger generation of Java.
\end{abstract}

Keywords: selection, defense, language, young generation of Java.

\section{Intisari}

Penelitian ini bertujuan mengungkap nasib bahasa bahasa Jawa di satu sisi dan bahasa Indonesia di sisi lain melalui pemilihan dan pemertahanan bahasa (Indonesia dan Jawa) oleh generasi muda. Bagiamana kaum muda memilih bahasa sebagai alat ekspresinya pada ranah rumah dan ranah persahabatan. Untuk menjawab pertanyaan tersebut dilakukan (a) menentukan lokasi dan populasi serta sampel, (b) penyebaran angket ke sejumlah responden yang kemudian dianalisis secara kualitatif dan kuantitatif, (c) observasi nonpartisipan pada kehidupan sehari-hari generasi muda, (d) wawancara terstruktur dan mendalam dengan menggunakan metode snowball yang kemudian dianalaisis secara kualitatif. Populasi penelitin ini adalah seluruh generasi muda Jawa yang tingal di Jawa Tengah. Adapun populasi sasaran penelitian ini adalah generasi muda dari berbagai daerah yang tinggal di Solo, Boyolali, Pekalongan, dan Tegal, sedangkan sampel dipilih secara acak. Hasilnya menunjukkan bahwa (1) generasi muda Jawa lebih banyak mengunakan BI (Bahasa Indonesia) daripada bahasa Jawa (BJ) baik pada ranah rumah maupun persahabatan, (2) generasi muda Jawa akan menggunakan 100 \% BI ketika kelak memiliki pasangan hidup, (3) 
generasi muda Jawa memiliki sikap negatif terhadap BJ, bersikap abai terhadap BI, dan tidak bangga terhadap BI, (4) generasi muda lebih familiar terhadap kosakata-kokata seperti download, stakeholder, gadget, daripada padan katanya dalam BI, dan (5) diperkirakan BJ (terutama ragam krama) pada 2 atau 3 generasi mendatang akan ditinggalkan oleh generasi muda Jawa.

Kata Kunci: pemilihan, pemertahanan, bahasa, generasi muda Jawa.

\section{Pendahuluan}

UU RI No.24/Tahun 2009 mengamanatkan bahwa bahasa Indonesia wajib digunakan dalam (a) dokumen resmi negara, (b) digunakan sebagai pengantar dalam pendidikan nasional, (c) digunakan dalam pelayanan administrasi, (d) digunakan dalam nota kesepahaman, (d) digunakan dalam forum nasional/internsional, (e) digunakan dalam lingkungan kerja pemerintah/swasta, (f) digunakan dalam karya dan atau publikasi ilmiah, (g) digunakan dalam media massa, (g) pemerintah wajib mengembangkan, membina, dan melindungi bahasa dan sastra Indonesia'; sedangkan terhadap bahasa daerah hanya memuat satu pasal, yaitu (a) pemerintah daerah wajib mengembangkan, membina, dan meindungi bahasa dan sastra daerah.

Keputusan politik bahasa di atas menggambarkan (a) tentang bagaimana pemerintah memperlakukan bahasa Indonesia dan bahasa daerah. Bahasa Indonesia didesain sedemikian rupa agar posisi dan kedudukannya kuat dan bahkan dominan dalam konteks sebagai korpus, status, maupunpemakaiannya di masyarakat. Oleh karena itu, tidak heran jika selama kongres bahasa dilaksanakan lebih banyak upaya yang dilakukan agar bahasa Indonesia menjadi "bahasa tunggal”. Begitu juga pasal-pasal yang mengatur tentang bahasa Indonesia dalam UU No24/2009 lebih dari 15 pasal, sedangkan bahasa daerah hanya diwadahi dalam 1 pasal. Maka tidak heran jika banyak bahasa daerah yang punah, terancam punah, merihatinkan. Padahal bahasa daerah merupakan kekayaan budaya yang tak ternilai. Sebagai contoh, data dari tahun 2011 s.d. 201 saja tercatat dari 71 bahasa daerah yang diuji "daya tahan hidupnya", tinggal 19 bahasa daerah dinyatakan aman, sedangkan sisanya memrihatinkan. Badan Bahasa juga memastikan 11 bahasa daerah di Indonnesia dinyatakan punah, 4 bahasa dalam kondisi kritis, 19 bahasa terancam punah, 2 bahasa mengalami kemunduran, dan 16 bahasa dalam keadaan rentan (Kompas, 21 Februari 2018 “11 Bahasa Daerah Sudah Punah”).

Paparan di atas baru menguraikan tentang relasi dan persaingan antara bahasa Indonesia dan bahasa daerah. Belum lagi persoalannya dengan bahasa asing, khususnya bahasa Inggris. Bahasa Inggris menurut Alwasilah (1997) menjadi kendala dan potensi yang 
kuat untuk "mengancam " kedudukan dan peran bahasa Indonesia apalagi bahasa daerah. Tanda-tanda tersebut sudah mulai tampak, misalnya dalam berbagai kegiatan sosial, ekonomi, dan bahkan pergaulan, bahasa Inggris tampak lebih dominan pemakaiannya. Jika hal ini dibiarkan, dampaknya adalah sikap positif terhadap bahasa Indonesia dan apalagi terhadap bahasa daerah akan semakin menurun dan lebih jauh lagi dapat menurunkan rasa cinta terhadap bahasa Indonesia dan bahasa daerah.

Data dan paparan di atas menggambarkan bahwa masalah kebahasaan merupakan masalah yang kompleks.Hal itu karena berkaitan dengan (a) bahasa, (b) pemakai bahasa, dan (c) pemakaian bahasa.Hasan Alwi dan Dendy Sugono, 2011: 6). Kompleksitas masalah kebahasaan tersebut sudah disadari oleh para ilmuwan (bahasa), pemerhati, dan pemerintah. Hal itu tampak, misalnya, pada kongres bahasa VIII dan IX. Hasil Kongres bahasa Indonesia VIII antara lain menyimpulkan bahwa (1) arus globalisasi di Indonesia telah menimbulkan perubahan dalam berbagai bidang dan telah memberikan dampak yang kurang menguntungkan terhadap perkembangan bahasa-bahasa di Indonesia. Bahasa Indonesia, apalagi bahasa daerah seakan-akan menjadi subordinasi dari bahasa asing yang perannya begitu penting dalam komunikasi di bidang ipteks dan ekonomi. Oleh karena itu, agar tidak mengancam kebhinekaan, bahasa Indonesia harus tetap mempertahankan perannya sebagai alat pemersatu, pembentuk jati diri, pemandirian bangsa, dan wahana komunkasi yang dapat membawa banagsa ke dalam kehidupan yang lebih modern dan beradab, (2) peran bahasa daerah, termasuk aksaranya sebagai sarana pengmbangan dan pembinaan kebudayaan, pendidikan, seni, dan tradisi daerah untuk memperkukuh jati diri dan ketahanan budaya bangsa perlu ditingkatkan. Oleh karena itu, pemantapan peran bahasa daerah perlu dikaji secara mendalam, Di samping itu, peningkatan peran tersebut, juga dapat dilakukan melalui ranah kebudayaan, agama, dan adat. Sementara, hasil kongres Internasional IX Bahasa Indonesia menghasilkan putusan antara lain (1) untuk memartabatkan bahasa Indonesia, terutama di luar negeri, penyebarluasan hasil penelitian dan pengembangan bahasa melalui kongres/seminar/konferensi internasional, dan publikasi ilmiah perlu ditingkatkan, (2) untuk meningkatkan peran bahasa Indonesia sebagai bagian dari jati diri bangsa; terhadap bahasa daerah (1) pendokumentasian bahasa daerah sebagai perwujudan peta wilayah dan budaya perlu terus dilakukan dan disempurnakan, (2) untuk menjaga ketahanan bahasa dan sastra daerah hendaknya kedudukan serta fungsi bahasa dan sastra daerah di tengah-tengah kehidupan bahasa Indonesia dan bahasa asing dimantapkan, (3) pelestarian bahasa daerah, termasuk aksaranya, baik melalui jalur pendidikan formal, nonformal, maupun informal perlu 
dilakukan secara berkelanjutan dan diatur dalam peraturan pada tingkat pusat dan daerah (Yeyen Maryani, 2011 dalam Kumpulan Putusan Kongres Bahasa Indonesia I - XI Tahun 1938 - 2008 ). Oleh karena itulah, diperlukan perencanaan bahasa. Perencanaan bahasa pada dasarnya menyangkut (a) aspek korpus, (b) aspek status, dan (c) aspek pemerolehan bahasa.Lalu, pertanyaannya bagaimana realitasnya dalam kehidupan masyarakat dalam berbahasa daerah dan atau berbahasa Indonesia? Berikut dipaparkan sejumlah penelitian tentang pemakaian bahasa Indonesia dan bahasa daerah.

Penelitian Puji Hidayati (2013)menyimpulkan bahwa di kalangan anak muda (anak band) telah terjadi (1) pergeseran bahasa dalam bentuk (a) kata, (b) frasa, dan, (c) klausa, sedangkan Lustanti Septiningsih (2016) dokumentasi budaya daerah dapat dijadikan rujukan dalam bahan ajar bahasa dan pengajaran sastra bagi siswa. Ririen Ekoyanantiasih (2015) menyatakan bahasa Jawa digunakan secara dominan dalam ranah keluarga. Akan tetapi, penelitian (Syaifudin, 2008) menyebut pada masyarakat perbatasan (Losari, Brebes) telah terjadi pergeseran dari bahasa Jawa ke bahasa Sunda dan atau sebaliknya secara terpola yaitu: (1) pola hubungan suami ke istri, (2) pola hubungan istri ke suami, (3) pola hubungan orang tua ke anak, dan (4) pola hubungan anak ke orang tua.Pola hubungan suami ke istri.Hal senada juga ditunjukkan pada hasil penelitian Suharyo (2015) yang menemukan tiga pola pemilihan, yaitu (1) yang lebih sering atau hampir selalu menggunakan BI, (2) yang lebih sering atau hampir selalu menggunakan BJ, dan (3) yang sama seringnya antara penggunaan BJ dan BI, (2) masyarakat Semarang sedang mengalami pergeseran dari masyarakat yang berlapis-lapis dan tertutup ke masyarakat yang (berlapis) terbuka.

Hasil penelitian Sundari (2016) menyebut bahwa input bahasa ibu sangat signifikan dalam hal pemerolehan bahasa anak, sedangkan Solikhah (2015) mengatakan bahwa pria dan wanita memiliki perbedaan dari sisi komunikasi verbal. Wanita cenderung "bawel", laki-laki ketika bebicara berdasarkan data dan fakta. Sementara, penelitian Savitri (2015) menyimpulkan bahwa smartphone telah mengubah pola interaksi antara anak dan ayahnya, sedangkan hasil penelitian Tabrani dan Prasetyoningsih (2017) menjelaskan tentang model pemertahanan bahasa Jawa melalui budaya lokal guyub tutur yang diwujudkan dalam bentuk DVD.

Berangkat dari permasalahan di atas, pertanyaannya adalah bagaimana generasi muda Jawa dalam memilih bahasa sebagai alat ekspresinya ketika berinteraksi di ranah rumah dan ranah sosial dengan anggota keluarga dan atau dengan sesamanya?Bagaimana generasi muda 
Jawa dalam memilih bahasa sebagai alat ekspresinya ketika berinteraksi di ranah rumah dan ranah sosial dengan anggota keluarga dan atau dengan sesamanya ?

Dalam berbagai literatur yang penulis telusuri, dijelaskan bahwa pemertahanan bahasa dan pergeseran bahasa ibarat dua sisi dari satu mata uang yang tidak dapat dipisahkan. Keduanya merupakan hasil kolektif dari pemilihan bahasa. Sementara, faktor-faktor penting pemertahanan sebuah bahasa adalah adanya, pengalihan bahasa kepada generasi penerusnya, keyakinan, dan loyalitas masyarakat pendukungnya. Dengan loyalitas itu, pendukung suatu bahasa akan tetap mentransmisikan bahasanya dari generasi ke generasi. Sumarsono (1990: 27) dalam disertasinya mengatakan bahwa konsentrasi wilayah permukiman adalah salah satu faktor yang dapat mendukung kelestarian sebuah bahasa. Konsentrasi wilayah permukiman merupakan faktor penting dibandingkan dengan jumlah penduduk yang besar. Kelompok yang kecil jumlahnya pun dapat lebih kuat mempertahankan bahasanya, jika konsentrasi wilayah permukiman dapat dipertahankan, sehingga terdapat keterpisahan secara fisik, ekonomi, dan sosial budaya.

Penelitian Puji Hidayati (2013) menyimpulkan bahwa di kalangan anak muda (anak band) telah terjadi (1) pergeseran bahasa dalam bentuk (a) kata (b) frasa, dan (c) klausa, sedangkan Lustanti Septiningsih (2016) dokumentasi budaya daerah dapat dijadikan rujukan dalam bahan ajar bahasa dan pengajaran sastra bagi siswa. Ririen Ekoyanantiasih (2015) menyatakan bahasa Jawa digunakan secara dominan dalam ranah keluarga. Baik itu kepada orang tua, istri, anak, dan sanak keluarga. Adapun bahasa yang digunakan antara lain ngoko, ngoko alus, krama lugu, dan krama alus. Adapun faktor yang menyebabkan pemertahanan bahasa Jawa adalah keyakinan, kesantunan, demografis, dan loyalitas. Keyakinan berhubungan dengan kepercayaan bahwa bahasa ibu adalah yang pertama dan utama yang harus diajarkan kepada anak. Bahasa ibu akan menuntun anak mempelajari bahasa kedua, ketiga, dan seterusnya. Selain itu, menanamkan bahasa Jawa juga sebagai wujud kepedulian kepada kelangsungan bahasa.

Ahmad Syaifudin (2008) dalam hasil penelitiannya menunjukkan bahwa masyarakat wilayah perbatasan Jawa-Sunda dalam ranah keluarga di Losari Kabupaten Brebes telah mengalami pergeseran bahasa berdasarkan peran masing-masing anggota keluarga yang membentuk pola-pola hubungan yang teratur pada masyarakat Jawa pada wilayah perbatasan Jawa-Sunda di Losari Kabupaten Brebes, yaitu: (1) pola hubungan suami ke istri, (2) pola hubungan istri ke suami, (3) pola hubungan orang tua ke anak, dan (4) pola hubungan anak ke orang tua.Pola hubungan suami ke istri. Misal, Suami menggunakan bahasa Sunda kasar 
ketika berbicara dengana istri. Hal itu dilakukan agar hubungan di antara mereka dapat berlangsung akrab, santai, dan dapat saling dipahami. Dengan demikian, akibat perbedaan kemampuan penguasaan bahasa, perbedaan latar belakang etnis, kedekatan hubungan kekerabatan, dan situasi tutur dalam peristiwa tutur antara suami dan istri tersebutmenyebabkan pergeseran bahasa Jawa di Losari terjadi.

Penelitian Suharyo (2015) menemukan tiga pola pemilihan, yaitu (1) yang lebih sering atau hampir selalu menggunakan BI, (2) yang lebih sering atau hampir selalu menggunakan BJ, dan (3) yang sama seringnya antara penggunaan BJ dan BI, (2) masyarakat Semarang sedang mengalami pergeseran dari masyarakat yang berlapis-lapis dan tertutup ke masyarakat yang (berlapis) terbuka, (4) variabel yang mempengaruhi pemilihan bahasa adalah faktor tempat (penampilan), faktor keintiman/keakraban, dan faktor keresmian atau keformalan.

Hasil penelitian Suharyo (2106) tentang pemilihan kode bahasa di kalangan generasi muda non-Jawa menyebutkan bahwa telah terjadi persaingan antara bahasa Indonesia dan bahasa daerah. Di ranah rumah masih relatif berimbang, tetapi di ranah pergaulan sudah lebih banyak menggunakan bahasa daerah $(70 \%)$. Responden juga mengatakan bahwa bahasa Indonesia lebih bergengsi lebih penting dibandingkan dengan bahasa daerah.

Sikap bahasa kaum ibu perkotaan pada penelitian Suharyo (2017) dikemukakan bahwa (a) ibu lebih banyak menggunakan bahasa Jawa daripada bahasa Indonesia, tetapi sebaliknya (b) ketika berbicara dengan anak, kaum ibu lebih banyak menggunakan bahasa Indonesia daripada bahasa Jawa, dan (c) mereka sebagian besar masih mengharapkan bahasa Jawa diajarkan baik di sekolah maupun di rumah (87,50\%) dan diajarkan di rumah 12,50 \%; (d) kemampuan bahasa Jawa responden sangat baik (12,50 \%), baik (67,50 \%), kurang baik (20\%). Hasil penelitian Sundari (2016) menyebut bahwa input bahasa ibu sangat signifikan dalam hal pemerolehan bahasa anak, sedangkan Solikhah (2015) mengatakan bahwa pria dan wanita memiliki perbedaan dari sisi komunikasi verbal. Wanita cenderung "bawel", laki-laki ketika bebicara berdasarkana data dan fakta. Sementara, penelitian Savitri (2015) menyimpulkan bahwa smartphone telah mengubah pola interaksi antara anak dan ayahnya. Sementara, hasil penelitian Prasetyoningsih (2017) menjelaskan tentang model pemertahanan bahasa Jawa melaluibudaya lokal guyub tutur yang diwujudkan dalam bentuk DVD.

Perbedaan penelitian ini dengan penelitian-penelitian sebelumnya terletak pada (a) subjek yang diteliti. Penelitian ini memfokuskan pada kaum perempuan, sedangkan penelitian-penelitian sebelumnya masih secara umum masyarakat); (b) penelitian sebelumnya 
baru dalam taraf mendeskripsikan belum menjawab pertanyaan mengapa hal itu terjadi (misalnya mengapa bahasa Jawa terancam punah, mengapa bahasa Indonesia mendominasi, dst.). Selain itu, penelitian ini memiliki kebaruan dalam hal (a) (rencana) dihasilkannya bahan ajar metode penelitian (bahasa secara) secara sosiolinguistik, (b) model pemertahanan bahasa Jawa berbasis budaya/tradisi lokal.

Kerangkan teoretik dalam penelitian ini didasarkan pada teori dan hasil-hasil peneitian sebelumnya. Bahasa dalam pandangan sosiolinguistik tidak pernah berada di ruang hampa sosial. Artinya, bahasa selalu ditempatkan pada konteks sosialnya tempat bahasa tersebut tumbuh dan digunakan oleh penuturnya. Jadi, gejala bahasa "tidak direduksi" hanya menjadi bahasa yang berstruktur dan atau bersistem" (sebagaimana aliran struktural)sehingga melahirkan linguistik an sich. Misal, pemilihan sapaan, seperti papa, mama, abi, umi, pake, mbokepada masyarakat tertentu tidak dilihat semata-mata penggunaan kata-kata sapaan terbut. Akan tetapi, pemakaian sapaan tersebut disebabkan oleh struktur sosial/latar belakang sosial pengguna sapaan tersebut.Pemilihan sapaan pake dan mboke, misalnya merujuk pada konteks sosial desa, pada keluarga Jawa (yang stratifikasi sosialnya menengah). Sementara, sapaan abah/abi dan umi merujuk pada latar belakang sosial yang pemakaianya kuat dalam pemahaman agama Islam.

Dalam konteks teoretik, pemilihan bahasa senantiasa terkait dengan konsep variasi bahasa, dwibahawasan/multibahaswan, ranah, giglosia, dan "kebocoran" diglosia". Secara sosiolinguistik, bahasa diyakini tidak pernah monolitik, tetapi selalu bervariasi. Oleh karena itu, di dalam kehidupan berbahasa, seorang penutur selalu dihadapkan pada pilihan-pilihan bahasa/ragam. Untuk dapat memilih salah satu atau bahkan keduanya, dipelukan kemampuan menguasai dua atau lebih bahasa/ragam. Maka dari itu, seseorang akhirnya menjadi dwibahasawan/multibahasawan.

Pada masyarakat yang dwibahasawan/multibahasawan seseorang harus mengetahui fungsi dan peran antara satu bahasa/ragam dengan bahasa/ragam lainnya. Kondisi masyarakat semacam ini lazim disebut sebagai masyarakat yang diglosik. Pada masyarakat yang diglosik, penutur akan mampu memahami dan membedakan bahasa/ragam yang digunakan pada ranah satu dengan ranah lainnya. Misal, bahasa/ragam bahasa Jawa ngoko, misalnya, dirasa lebih tepat digunakan pada ranah rumah; sedangkan bahasa Indonesia lebih tepat jika digunakan pada ranah pendidikan. Jika terjadi "pelanggaran" (misalnya, bahasa daerah digunakan pada ranah rumah, maka pada masyarakat tersebut sedang terjadi "kebocoran" diglosia. 
Dalam konteks hasil-hasil penelitian terdahulu, dalam penelitian ini terdapat sejumlah hal yang penting dikemukakan sebagai kerangka acuan penelitian ini. Misal, yang menyangkut faktor (a) penguat dan (b) pelemah dalam pemilihan dan pemertahanan bahasa. Selain itu, sejumlah metode yang juga digunakan dalam penelitian ini, seperti (a) observasi, (b) wawancara, (c) rekam, (d) catat, (e) angket, dan (f) snowball.

\section{Metode Penelitian}

\section{Lokasi Penelitian}

Peneleitian ini mengambil Jawa Tengah sebagai lokasi penelitian. Adapun, wilayah yang dijadikan titik pengamatan meliputi Solo, Boyolali, Pekalongan, dan Brebes. Dua awilayah pertama dinilai mewakili daerah yang dekat dengan wilayah kraton Surakarta sehingga dihipotesis masih "mempertahankan" bahasa dan budaya Jawa; sedangkan dua wilayah terakhir (Pekalongan dan Tegal) mewakili masyarakat pesisir yang "jauh" dari pusat kraton dan termasuk Jawa Tengah bagian barat.

\section{Populasi dan Sampel}

Populasi penelitian ini adalah seluruh generasi muda Jawa di Jawa Tengah yang tinggal di Jawa Tengah. Adapun sampel yang diambil bersifat acak terhadap generasi muda Jawa yang tinggal di Solo, Boyolali, Pekalongan, dan Tegal.

Pengumpulan Data

Pengumpulan data dilakukan dengan pengamatan, angket, dan wawancara terstruktur terhadap sejumlah informan, sedangkan angket didistribusikan kepada generasi muda yang secara acak dengan jumlah 50. Dari 50 angket, 45 angket yang dinilai valid untuk bahan analisis.Data dianalsisis dengan metode kualitatif dan kuantitatif. Metode kualitatif terutama untuk menganalisis data dari hasil wawancara, sedangkan metode kuantitatif dilakukan untuk menganalisis dari sumber data berupa angket.Hasil penelitian disajikan dengan metode informal, yaitu berupa kata-kata biasaa, bukan mengunakan rumus-rumus dan lambanglambang sebagaimana yang lazim digunakan dalam ilmu eksakta.

\section{Hasil dan Pembahasan}

Berdasarkan data yang telah dikumpulkan diperoleh hasil sebagai berikut.

1. Penggunaan/pemilihan bahasa para generasi muda Jawa pada ranah rumah dan persahabatan

(1) Bahasa sehari-hari yang digunakan generasi muda Jawa di ranah rumah ( dengan ayah, ibu, dan atau saudara: kakak/adik) adalah (a) menggunakan bahasa Indonesia 
sebanyak $55 \%$, (b) menggunakan bahasa Jawa 24,45 \%, dan (c) mengunakan bahasa campuran (Indonesia dan Jawa) sebanyak $20 \%$.

(2) Bahasa yang digunkan generasi muda Jawa ketika berbicara dengan sahabat/teman sebayanya pada ranah persahabatan, diperoleh hasil (a)generasi muda Jawa yang mengunakan bahasa Indonesia ketika berbicara dengan teman sebaya sebanyak 55,55 $\%$, (b) yang menggunakan bahasa Jawa sebanyak 17, $78 \%$, dan menggunakan bahasa campuran sebanyak 26, $67 \%$.

(3) Pada ranah persahabatan, generasi muda Jawa dalam menggunakan bahasa ketika berbicara dengan teman tidak sebaya, diperoleh hasil (a) menggunakan bahasa Indonesia sebanyak 77, 78 \%, (b) yang menggunakan bahasa Jawa sebanyak 22, 22 $\%$. Dari data ayang terkumpul tidak ditemukan yang menggunakan bahasa campuran.

2. Rencana penggunaan/pemilihan bahasa kelak ketika berumah tangga.

Bahasa yang diggunakan ketika berbicara dengan anak(-anak)nya kelak, semua responden (100\%) menjawab akan menggunakan bahasa Indonesia.

3. Pengetahuan generasi muda Jawa terhadap penulisan kata/gabungan kata yang sesuai kaidah bahasa Indonesia, seperti pandanaran hills, agnes salon, dan sun motor. Jawaban responden atas pertanyaan di atas (penulisan dan pengetahuan struktur gabungan kata yang sesuai kaidah bahasa Indonesia), diperoleh hasil:

(a) Responden yang menjawab belum sesuai kaidah, tetapi jawabannya salah sebanyak $(51.11 \%)$

(b) Responden yang menjawab bahwa struktur/penlisan gabungan kata seperti contoh di atas ( pandanaran hills, dll.) sesuai kaidah sebanyak 44,45\%

(c) Responden yang tidak menjawab bahwa struktur gabungan kata di atas sesuai/tidak sesuai dengan kaidah bahasa Indonesia sebanyak 4, $44 \%$

\section{Sikap dan Pengetahuan Generasi Muda terhadap Bahasa dan Makna Kata/Istilah}

Ketika responden ditanya terkait dengan pengetahuan dan makna/arti kata, seperti stakeholders, gadget, selfie, showroom; sebagian besar responden $90 \%$ tidak tahu. Mereka juga mengatakan suka menggunakan kata-kata tersebut dibandingkan padan katanya dalam bahasa Indonesia. Di samping itu, mereka juga menjawab lebih tahu/familiar kata-kata tersebut. Ketika responden ditanya, "Lebih suka mana kata-kata tersebut dibandingkan padan katanya dalam bahasa Indonesia"? Hampir semua responden 
menjawab lebih suka menggunakan kosakata (stakeholders, gadget, selfie, dll.) daripada padan katanya dalam bahasa Indonesia (pemangku kepentingan, gawai, swafoto).

Meskipun sebagian besar responden tidak tahu, tidak familiar (khususnya dengan katakata, seperti gadget, stakeholders dll., para responden masih menganggap bahwa bahasa Indonesia berhubungan dengan nasionalisme (77, $78 \%$ ), dan sisanya (22, $22 \%)$ menganggap bahasa Indonesia tidak berhubungan dengan nasionalisme.

\section{Sikap Bahasa Generasi Muda Jawa dan Nasib Bahasa Jawa pada Masa Mendatang}

Dari data yang telah dikumpulkan dapat diketahui bahwa generasi muda Jawa sudah mulai tidak bangga terhadap bahasa Jawa. Sikap bahasanya (terhadap bahasa Jawa) cenderung negatif, sedangkana terhadap bahasa Indonesia generasi muda Jawa menunjukkan terdapat gejala tidak setia dan kesadaran atas norma bahasa Indonesia lemah. Dari data pula diketahui nasib bahasa Jawa (terutama ragam krama) akan segera ditinggalkan oleh penuturnya pada 2 sampai 3 generasi mendatang.

Dari hasil analisis data yang telah diuraikan di atas terdapat sejumlah bahasan. Pertama, bahasa Indonesia telah secara dominan "menguasai" pikiran generasi muda Jawa sehingga lebih banyak dipilih sebagai alat ekspresi dan interaksi baik di ranah rumah maupun di ranah persahabatan. Dengan demikian, telah terjadi apa yang Fishman disebut sebagai "kebocoran" diglosia. "Kebocoran" diglosia terjadi manakala bahasa daerah yang selama bertahun-tahun menjadi alat ekspresi utama di ranah rumah kemasukan bahasa kedua/bahasa lain (dalam hal ini bahasa Indonesia). Kedua, ancaman bahasa Indonesia terhadap bahasa Jawa semakin signifikan jika dikaitkan dengan temuan pemilihan bahasa oleh generasi muda Jawa pada ranah persahabatan, Pada ranah ini, sebagian besar generasi muda Jawa (77 \% lebih) lebih memilih bahasa Indonesia dibandingkan dengan bahasa Jawa yang hanya $20 \%$-an ketika berbicara dengan teman yang tidak sebaya, Padahal, masyarakat Jawa zaman dulu akan lebih mengunakan bahasa Jawa ragam krama ketika berbicara dengan orang yang lebih tua/tidak sebaya. Gejala ini menunjukkan bahwa generasi muda Jawa sudah mulai meninggalkan bahasa Jawa yang dinilainya menyulitkan sebagai alat komunikasi. Nilai-nilai Jawa sudah mulai tidak dijadikan acuan dalam berpikir, berekspresi, dan bertindak oleh para generasi muda Jawa dan menggantinya dengan nilai-nilai Indonesia yang cenderung egaliter. Bahkan generasi muda Jawa akan benar-benar menkinggalkan bahasa Jawa ketika kelak sudah memiliki pasangan hidup. Ketiga, gejala bahasa Jawa akan ditinggalkan oleh generasi muda 
Jawa semakin diperkuat dengan temuan tentang sikap berbahasanya, yang cenderung negatif terhadap bahasa Jawa. Keempat, generasi muda Jawa mulai menggunakan nilai-nilai global dalam menyikapi ekspresi kebahasannya. Hal itu ditandai dengan (a) sikap bahasa generasi muda Jawa terhadap bahasa Jawa negatif, (b) sikap bahasa generasi muda Jawa terhadap bahasa Indonesia tidak bangga, dan abai terhadap norma bahasa Indonesia, (c) tetapi terhadap bahasa Inggris, sikap bahasa generasi muda Jawa terhadap bahasa Inggris bersifat positif, terdapat gejala lebih suka menggunakan bahasa Inggris, dan lebih familiar terhadap bahasa Inggris dibanding dengan bahasa Indonesia meski baru terbatas pada penggunaan sejumlah kosakata teretentu, seperti pandanaran hills, shoroom, download, gadget, netizen, stakeholder. Semua hasil penelitian ini tentang (terutama) nasib bahasa Jawa diduga disebabkan perencanaan bahasa yang lebih mengutamakan bahasa Indonesia daripada bahasa daerah dan politik bahasa melalui UU No. 24/2009.

\section{Simpulan}

Dari paparan di atas dapat disimpulkan beberapa hal. Pertama, bahasa Indonesia sudah lebih diminati generasi muda Jawa sebagai pilihan utama sebagai alat ekspresi di dalam ranah rumah ketika berbicara dengan ayah, ibu, dan saudaranya (kakak/adik). Kedua, telah terjadi "kebocoran" diglosia. Hal itu, ditandai ketika bahasa nasional (bahasa Indonesia) telah masuk pada ranah rumah. Ketiga, para generasi muda juga lebih memilih bahasa Indonesia dibandingkan bahasa Jawa ketika berbicara dengan teman sebaya. Apalagi ketika berbicara dengana teman yang tidak sebaya, pemilihan bahasa Indonesia telah mencapai $77 \%$ lebih digunakan oleh generasi muda Jawa. Keempat, generasi muda Jawa bahkan akan menggunakan $100 \%$ bahasa Indonesia ketika berbicara dengan pasangannya kelak. Kelima, pengetahuan akan norma bahasa Indonesia; generasi muda Jaa relatif rendah. Keenam, generasi muda Jawa cenderiung bersikap negatif terhadap bahasa Jawa. Ketujuh, generasi muda bersikap kurang menghargai norma bahasa Indonesia dan menunjukkan sikap kurang bangga terhadap bahasa Indonesia. Kedelapan, bahasa Jawa (terutama ragam krama) pada 2 sampai denga 3 generasi mendatang diperkirakan akan ditinggalkan penuturnya.

\section{Daftar Pustaka}

Alwi, Hasan. 2011. Bahasa Indonesia: Pemakai dan Pemakaianya. Jakarta: Badan Bahasa.

Mariani, Yeyen. 2011. Kumpulan Putusan Kongres Bahasa Indonesia I-XI tahun 19382008. Jakarta: Badan Bahasa. 
Savitri, Detania. 2015. Peran Teknologi Komunikasi dalam Interaksi Ayah dan Anak Studi Kasus: Interaksi Ayah dan Anak Melalui Smartphone.Kajian Ilmu Komunikasi Volume 45. Nomor 2. Desember 2015. Jakarta: Universitas Indonesia.

Sholikhah, Hani Atus. 2015. Bahasa Pria dan Wanita: Kajian Sosiolinguistis pada Mahasiswa Universitas PGRI Palembang. Jurnal Lentera Vol 2. STKIP-PGRI Bandar Lampung.

Suharyo. 2016. Pemilihan Kode Bahasa di Kalangan Generasi Muda non-Jawa. . Laporan Penelitian. Semarang: FIB Undip.

_2017. Pemilihan dan Sikap Bahasa Kaum Ibu di Kota Semarang. Laporan Penelitian. Semarang: FIB Undip.

Sumarsono. 1990. Pemertahanan Bahasa Melayu Loloan di Bali. Diertasi Universitas Indonesia Jakarta.

Sundari, Hana. 2016. Pengaruh Input Bahasa Orang Tua terhadap Kompleksitas Bahasa Anak: Studi Kasus Pada Anak Usia 5 Tahun Melalui Interactive Shared Reading. Jurnal Pendidikan Bahasa dan Sastra Vol. 16 No. 1. Universitas Indraprasta PGRI Jakarta.

Tabrani, Akhmad dan Luluk Sri Agus Prasetyoningsih. 2017. Pengembangan Pemertahanan Bahasa Jawa Melalui Budaya Lokal Guyub Tutur dalam Kajian Antropolinguistik. Jurnal Litera Vol. 16. No. 1, April 2017. Universitas Islam Malang.

Thohir, Mudjahirin. 1999. Wacana Masyarakat dan Kebudayaan Jawa Pesisiran. Semarang: Bendera.

Undang-Undang Republik Indonesia Nomor 24 Tahun 2009 tentang Bendera, Bahasa, dan Lambang Negara, serta Lagu Kebangsaan. Jakarta: Badan Pengembangan dan Pembinaan Bahasa Kementerian Pendidikan dan Kebudayaan. 